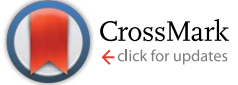

Cite this: RSC Adv., 2016, 6, 68092

\title{
Highly efficient dye-sensitized solar cell performance from template derived high surface area mesoporous $\mathrm{TiO}_{2}$ nanospheres
}
J. Archana, ${ }^{\text {ab }}$ S. Harish, ${ }^{b}$ M. Sabarinathan, ${ }^{b}$ M. Navaneethan, ${ }^{\text {b }}$ S. Ponnusamy, ${ }^{a}$ C. Muthamizhchelvan, ${ }^{a}$ M. Shimomura, ${ }^{b}$ H. Ikeda, ${ }^{b}$ D. K. Aswal ${ }^{c}$ and Y. Hayakawa*b

\begin{abstract}
High surface area mesoporous anatase $\mathrm{TiO}_{2}$ spheres are synthesized using ethylene glycol as a template by a solvothermal method. Electron microscopy studies revealed the formation of smooth surfaced mesoporous spheres with uniform size. A high surface area of $221.52 \mathrm{~m}^{2} \mathrm{~g}^{-1}$ is obtained for the titanium tetraisopropoxide concentration of $0.5 \mathrm{~mL}$. X-Ray diffraction and Raman analyses revealed the formation of anatase phase $\mathrm{TiO}_{2}$. Uniform deposition of a mesoporous film for a photoanode was achieved by an optimized spray deposition method. The effects of the ruthenium dye-sensitizer N719 and indoline dyesensitizer D205 on the dye sensitized solar cell performance are investigated. Maximum efficiencies of 8.96 and $9.02 \%$ are achieved using the sensitizers N719 and D205, respectively; from the mesoporous anatase $\mathrm{TiO}_{2}$ sphere coated DSSC. IPCE analyses revealed that the mesoporous spheres efficiently collected the incident photons and achieved a conversion efficiency over $80 \%$ by internal reflections and a scattering process.
\end{abstract}

Received 9th June 2016 Accepted 12th July 2016

DOI: $10.1039 / c 6 r a 14976 f$

www.rsc.org/advances
Much effort has been made to modify the structure of photoanode materials. Sung Hoon et al. ${ }^{20}$ prepared mesoporous $\mathrm{TiO}_{2}$ films using graft co-polymers as a template, achieving a maximum efficiency of $4.6 \%$. Satyanarayana Reddy et al. ${ }^{21}$ used a soft template method for preparing mesoporous $\mathrm{TiO}_{2}$ by employing various cationic surfactants as structure-directing and pore-forming agents. They achieved an efficiency of 7.5\%. Hun-Gi Jung et al. ${ }^{22}$ synthesized mesoporous $\mathrm{TiO}_{2}$ spheres by a urea-assisted hydrothermal process. The resulting mesoporous $\mathrm{TiO}_{2}$ electrode exhibited a higher efficiency (7.54\%) than a commercial P25 $\mathrm{TiO}_{2}$ electrode (5.69\%). Xiaohuan et al. ${ }^{23}$ had prepared mesoporous anatase $\mathrm{TiO}_{2}$ microspheres by solvothermal process using phenol as a solvent. The average diameter of the synthesized spheres was $3 \mu \mathrm{m}$ with the surface area of $168 \mathrm{~m}^{2} \mathrm{~g}^{-1}$. It yielded the conversion efficiency of $7.94 \%$. Yuli Xiong ${ }^{24}$ and his co-workers prepared highly ordered anatase 2D hexagonal mesoporous titania particles by ultrasonication method. Pluronic P123 was used as a surfactant template and $\mathrm{HCl}, \mathrm{H}_{2} \mathrm{SO}_{4}$ as an acidic catalyst. It has the surface area of $121 \mathrm{~m}^{2} \mathrm{~g}^{-1}$ and the device exhibited the efficiency of $4.93 \%$. Jia-de-peng et al. ${ }^{25}$ synthesized mesoporous $\mathrm{TiO}_{2}$ spheres by hydrothermal method with an average diameter of $500 \pm 60$ $\mathrm{nm}$ with the surface area of $108.1 \mathrm{~m}^{2} \mathrm{~g}^{-1}$. The photoanode made of these spheres yielded the cell efficiency of $6.18 \%$. Juti et al. ${ }^{26}$ had synthesized the mesoporous anatase $\mathrm{TiO}_{2}$ spheres by facile microwave assisted hydrothermal method. The average sizes of the spheres were around $800 \mathrm{~nm}$ with the surface area of $222 \mathrm{~m}^{2}$ $\mathrm{g}^{-1}$. The cell yielded the efficiency of $5.72 \%$. Peter Chen et al. $^{27}$ prepared mesoporous anatase $\mathrm{TiO}_{2}$ spheres by microwave 
assisted hydrothermal method. The size of the spheres was in the range of 400-600 $\mathrm{nm}$ with the surface area of $132.49 \mathrm{~m}^{2} \mathrm{~g}^{-1}$. The efficiency of the cell is $5.43 \%$. Under the optimum condition with the scattering layer, the conversion efficiency was increased to $6.92 \%$. Chang Soo et al. ${ }^{28}$ prepared mesoporous anatase $\mathrm{TiO}_{2}$ spheres by facile non hydrothermal method, synthesizing bulk calcinations process in which polymer ethyl cellulose were used a structure directing agent. Nanocrystalline layer exhibits the cell efficiency of $5.0 \%$, when the mesoporous $\mathrm{TiO}_{2}$ spheres were used as a scattering layer the efficiency was increased to $6.1 \%$. Luo Tu et al. ${ }^{29}$ fabricated the DSSC using mesoporous $\mathrm{TiO}_{2}$ microspheres. The average size of the spheres was $1.1 \mu \mathrm{m}$ with the surface area of $137 \mathrm{~m}^{2} \mathrm{~g}^{-1}$. The cell yielded the efficiency of $6.6 \%$. Hui Tong ${ }^{30}$ and his coworkers synthesized mesoporous $\mathrm{TiO}_{2}$ microspheres by sol-gel method. The average diameter of the spheres was about $0.5 \mu \mathrm{m}$. They had investigated the surface area and pore size of the spheres without template $\left(123 \mathrm{~m}^{2} \mathrm{~g}^{-1}, 6.2 \mathrm{~nm}\right)$, with template Pluronic F127 as a template $\left(148 \mathrm{~m}^{2} \mathrm{~g}^{-1}, 5.4 \mathrm{~nm}\right)$ and $\mathrm{TiO}_{2}$ aggregates $\left(107 \mathrm{~m}^{2} \mathrm{~g}^{-1}, 10.6 \mathrm{~nm}\right)$. $\mathrm{TiO}_{2}$ aggregates with higher pore size gives good efficiency of $5.6 \%$ whereas the cell efficiency for without and with template were reported as $3.6 \%$ and $4.1 \%$.

Photoanode materials consisting of mesoporous frameworks lead to good efficiencies. Their large surface area and interconnected network facilitate dye loading, charge transport, and light scattering. ${ }^{31}$ Moreover, the high surface area with interconnected mesoporous $\mathrm{TiO}_{2}$ spheres is required to obtain the high efficiency in DSSC. In this study, mesoporous anatase $\mathrm{TiO}_{2}$ spheres with high surface area were solvothermally prepared using ethylene glycol as a templating agent. The effect of the titanium tetraisopropoxide (TTIP) precursor concentration on the formation and functional properties was investigated. The mesospheres were used to prepare photoanodes by spray deposition method. The effects of the sensitizers N719 and D205 on dye-sensitized solar cells performance were investigated.

\section{Experimental method}

\subsection{Solvothermal growth of mesoporous $\mathrm{TiO}_{2}$ spheres}

All chemicals were purchased from Wako Chemicals (Japan) and were used without further purification. Two steps were typically followed to prepare the $\mathrm{TiO}_{2}$ mesospheres.

2.1.1 Formation of titania glycolate spheres. Titanium tetraisopropoxide $(0.5,1.0,1.5$ and $2.0 \mathrm{~mL})$ was added to ethylene glycol $(50 \mathrm{~mL})$. The solution was stirred for $5 \mathrm{~h}$ at room temperature, and then added to acetone bath $(150 \mathrm{~mL})$ containing trace water. The solution was stirred for $2 \mathrm{~h}$ to form a white suspension which was collected by centrifugation, thoroughly washed with distilled water and ethanol to remove impurities, and dried at $80{ }^{\circ} \mathrm{C}$ for $10 \mathrm{~h}$. The samples were termed as $\mathrm{S} 1(0.5 \mathrm{~mL}), \mathrm{S} 2(1.0 \mathrm{~mL}), \mathrm{S} 3(1.5 \mathrm{~mL})$ and $\mathrm{S} 4(2.0 \mathrm{~mL})$, respectively.

2.1.2 Formation of mesoporous $\mathrm{TiO}_{2}$ spheres. The titania glycolate spheres were dispersed in an equal volume of water and ethanol $(30 \mathrm{~mL})$, and stirred for $2 \mathrm{~h}$. The white solution was transferred to a $100 \mathrm{~mL}$ Teflon-lined stainless steel autoclave, and heated at $150{ }^{\circ} \mathrm{C}$ for $12 \mathrm{~h}$. The resulting product was collected and annealed at $300{ }^{\circ} \mathrm{C}$ for $2 \mathrm{~h}$.

\subsection{Characterization}

Surface morphologies were observed by field-emission scanning electron microscopy (FESEM) with a JEOL JSM 7001F microscope. Transmission electron microscopy (TEM) images were recorded using a JEOL JEM $2100 \mathrm{~F}$ microscope at an accelerating voltage of $200 \mathrm{kV}$. Crystalline phases were determined by X-ray diffraction (XRD), using a Rigaku diffractometer (RINT-2200, Japan, $\mathrm{CuK}_{\alpha}$ radiation) with a $0.02^{\circ} \mathrm{s}^{-1}$ scan rate. Raman spectra were obtained using a JASCO NR-1800 spectrometer. Ultraviolet-visible (UV-vis) absorption spectra were measured using a Shimadzu 3100 PC spectrophotometer (Japan). Fourier transform infrared (FTIR) spectra were recorded using a JASCO MFT 2000 spectrometer from $\mathrm{KBr}$ pellet samples. Current density and voltage $(I-V)$ characteristics were measured at an air mass of AM 1.5 (100 $\mathrm{mW} \mathrm{cm}^{-2}$ of simulated sunlight) by a JASCO solar simulator equipped with a Keithley picoammeter. Impedance analysis was performed using Solartron (model no. 1280C) Electrochemical Test System.

\subsection{Dye-sensitized solar cell fabrication}

The fabrication procedure was adopted from our previous report. ${ }^{31}$ Mesoporous $\mathrm{TiO}_{2}$ powder was dispersed in ethanol, and ground for 30 min using an ultrasonic processor. Five drops of triton-X were added to the solution as a binder. The solution was sprayed on FTO glass (Nippon Sheet Glass, $8.7 \Omega$ sq. ${ }^{-1}, 80 \%$ transparency in the visible range) at $150{ }^{\circ} \mathrm{C}$ by spray pyrolysis. The $\mathrm{TiO}_{2}$ films were annealed at $450{ }^{\circ} \mathrm{C}$ for $2 \mathrm{~h}$. The resulting photoanodes were soaked in an ethanol solution containing $0.03 \mathrm{M} \mathrm{di-}$ tetrabutylammonium cis-bis(isothiocyanato)bis(2,2" -bipyridyl-4,4'dicarboxylato)ruthenium(II) (N719) for $12 \mathrm{~h}$. The photoanode was clamped with a Pt-coated FTO counter electrode to form a sandwich-type cell. A redox electrolyte solution was filled between the electrodes by capillary action to form the cell. The electrolyte consisted of $0.6 \mathrm{M}$ dimethylpropylimidazolium iodide, $0.1 \mathrm{M}$ lithium iodide, $0.01 \mathrm{M}$ iodine, and $0.5 \mathrm{M}$ tetrabutylpyridine in acetonitrile (FUNCHEM, Tomiyama electrolyte company, Japan).

\section{Results and discussion}

Fig. 1-4 show FESEM and TEM images of the titania glycolate and $\mathrm{TiO}_{2}$ spheres. The TTIP concentrations used in the preparations were $0.5,1.0,1.5$ and $2.0 \mathrm{~mL}$ for Fig. 1-4, respectively. Fig. 1-4(a) show typical FESEM images of the titania glycolate spheres, which exhibited an average size of 100-200 nm and very smooth surfaces. Porous $\mathrm{TiO}_{2}$ spheres were formed after solvothermal treatment, as shown in Fig. 1-4(b). TEM images of the porous $\mathrm{TiO}_{2}$ spheres are shown in Fig. 1-4(c). The formation of the spherical structure depended on the precursor concentration. When the TTIP concentration was $0.5 \mathrm{~mL}$, the resulting $\mathrm{TiO}_{2}$ spheres exhibited good interconnectivity and defined boundaries as shown in Fig. 1(c). As the TTIP concentration increased to $1.0,1.5$ and $2.0 \mathrm{~mL}$, the morphology of the products became progressively more irregular. Defined boundaries 
were not observed in Fig. 2(c). High-magnification TEM images of products prepared from TTIP concentrations of 0.5, 1.0, 1.5 and $2.0 \mathrm{~mL}$ are shown in Fig. 1-4(d), respectively. Highresolution TEM (HRTEM) images are shown inset. The prepared materials exhibited good crystallinity with an average particle size of 5-8 $\mathrm{nm}$. Thus, the $\mathrm{TiO}_{2}$ mesosphere morphology could be tuned by the concentration of the TTIP precursor.

Brunauer-Emmett-Teller (BET) analysis was performed to determine the surface area of the $\mathrm{TiO}_{2}$ spheres, and to better understand their mesoporous frameworks. ${ }^{33}$ Fig. 5(a) shows $\mathrm{N}_{2}$ adsorption-desorption isotherms and pore size distributions estimated using the Barrett-Joyner-Halenda (BJH) analysis. Fig. 5(b) shows that all isotherms exhibited type IV behavior with $\mathrm{H} 1$ hysteresis loops, which is characteristic of mesoporous structures. The surface area of the samples prepared from various TTIP concentrations were determined from BET analysis. A TTIP concentration of $0.5 \mathrm{~mL}$ resulted in a surface area of $221.52 \mathrm{~m}^{2} \mathrm{~g}^{-1}$. TTIP concentrations of $1.0,1.5$ and $2.0 \mathrm{~mL}$ resulted in surface areas of 169.60, 166.52 and $133.68 \mathrm{~m}^{2} \mathrm{~g}^{-1}$, respectively. Thus, an increasing TTIP concentration resulted in decreased BET surface areas. This was in good agreement with the TEM results, which showed a similar trend.

The formation process of the mesoporous $\mathrm{TiO}_{2}$ is shown in Fig. 5(c). Titanium metal oxides contain moisture-sensitive alkoxide groups, so TTIP tends to hydrolyze during titania synthesis. A high hydrolysis rate leads to non-uniform products, so it is necessary to slow this process. Branched alkoxy ligands sterically suppress hydrolysis, so ethylene glycol was chosen to suppress hydrolysis by the nucleophilic substitution mechanism. The alkyl chain of ethylene glycol coordinates with $\mathrm{TiO}_{2}$ nuclei to form titania glycolate, ${ }^{32}$ according to:

$$
\mathrm{Ti}(\mathrm{OiPr})_{4}+2 \mathrm{HO}\left(\mathrm{CH}_{2}\right)_{2} \mathrm{OH} \rightarrow \mathrm{Ti}\left(\left(\mathrm{OCH}_{2}\right)_{2}\right)_{2}+4 \mathrm{iPrOH}
$$
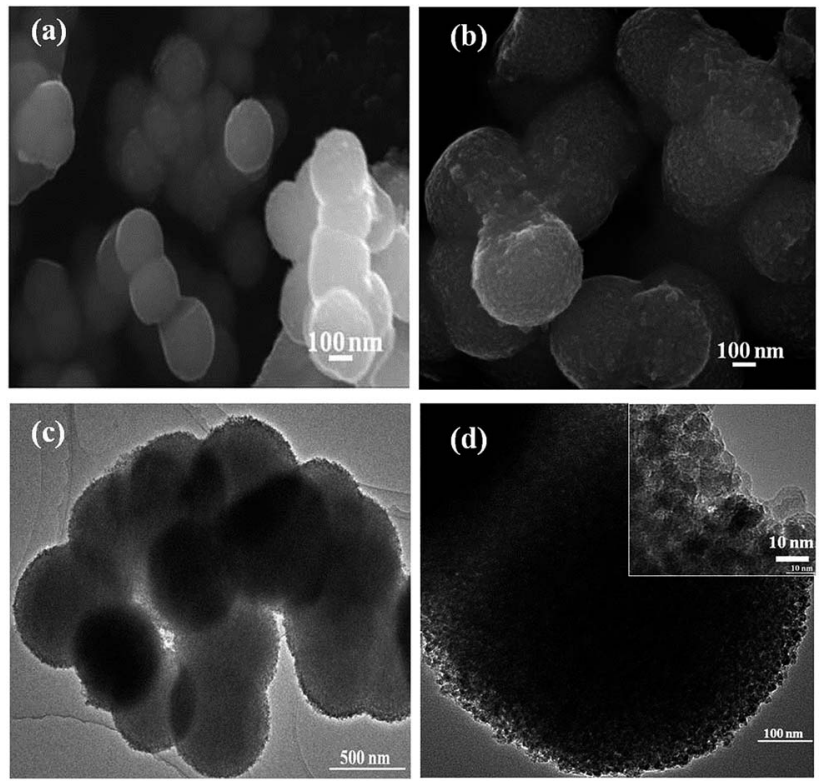

Fig. 1 FESEM images of (a) titania glycolate spheres and (b) mesoporous $\mathrm{TiO}_{2}$ spheres, (c)-(d) TEM images of mesoporous $\mathrm{TiO}_{2}$ spheres (inset shows a HRTEM image) of S1.
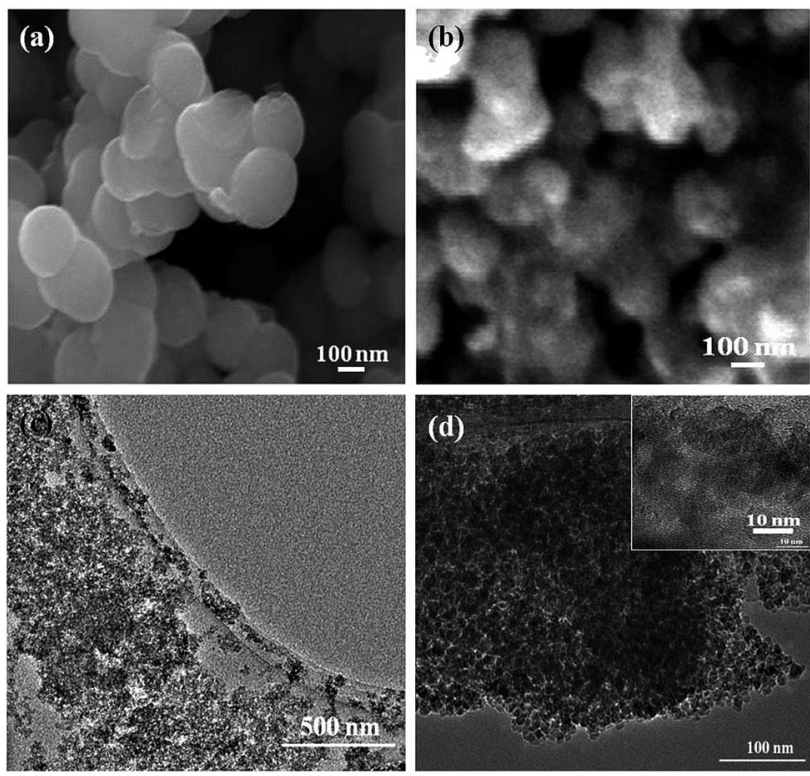

Fig. 2 FESEM images of (a) titania glycolate spheres and (b) mesoporous $\mathrm{TiO}_{2}$ spheres, (c)-(d) TEM images of mesoporous $\mathrm{TiO}_{2}$ spheres (inset shows a HRTEM image) of S2.

Titania glycolate was treated with acetone to enhance the hydrolysis of the glycolate precursor, and a solvothermal process was employed to synthesis the mesoporous anatase $\mathrm{TiO}_{2}$ spheres. During this process, coordination between the alkyl chain of ethylene glycolate and titania was broken. Releasing the alkoxy group from the product resulted in the mesoporous $\mathrm{TiO}_{2}$. TEM indicated that the increased TTIP concentration affected the structure of the $\mathrm{TiO}_{2}$ spheres. The number of $\mathrm{TiO}_{2}$ nuclei was proportional to the number of alkoxy
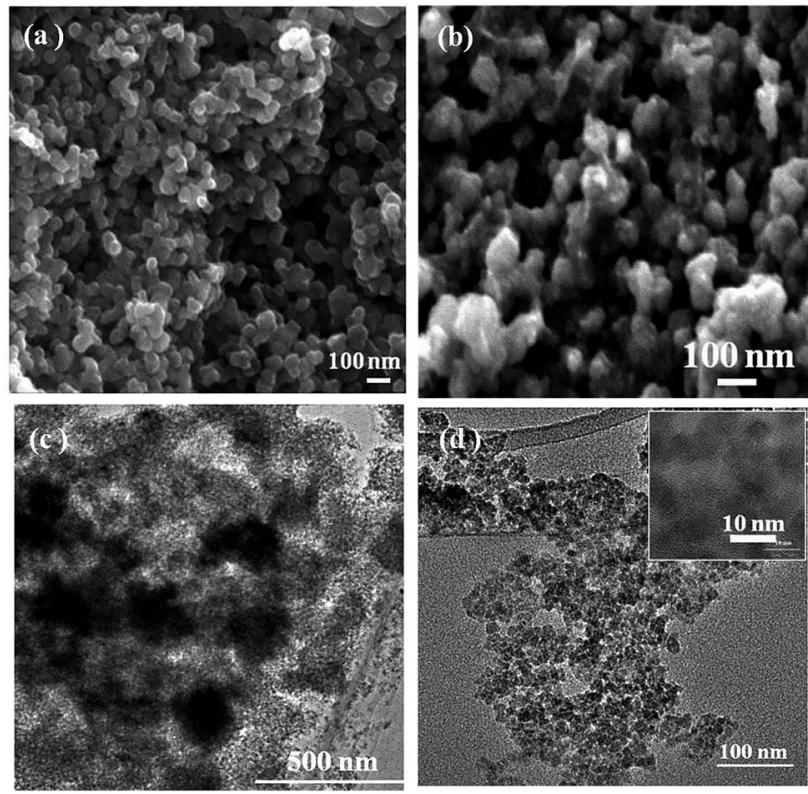

Fig. 3 FESEM images of (a) titania glycolate spheres and (b) mesoporous $\mathrm{TiO}_{2}$ spheres, (c)-(d) TEM images of mesoporous $\mathrm{TiO}_{2}$ spheres (inset shows a HRTEM image) of S3. 

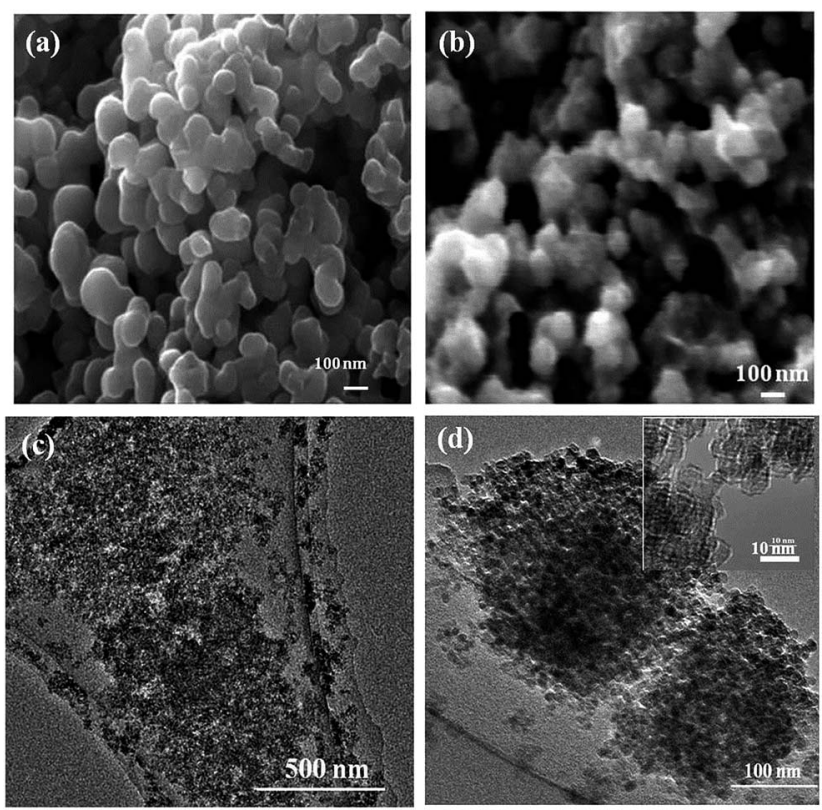

Fig. 4 FESEM images of (a) titania glycolate spheres and (b) mesoporous $\mathrm{TiO}_{2}$ spheres. (c)-(d) TEM images of mesoporous $\mathrm{TiO}_{2}$ spheres (inset shows a HRTEM image) of S4.

groups released from ethylene glycol. Increasing the TTIP concentration from 0.5 to $2.0 \mathrm{~mL}$ increased the number of $\mathrm{TiO}_{2}$ nuclei in solution. The alkyl chain content of ethylene glycol is constant, so the resulting imbalance in coordination bonds was responsible for the formation of the different surface morphology. Thus, the TTIP concentration played an important role in determining the particle morphology. $0.5 \mathrm{~mL}$ of TTIP evidently provided favorable coordination between $\mathrm{TiO}_{2}$ nuclei and alkyl chains, because defined interconnected structures were observed when comparing with higher TTIP concentration products.

Fig. 6(a) shows XRD patterns of the samples. Peaks at 25.19, 37.8, 48.1, 53.5, 55.1, 62.3, 70.2 and $75.2^{\circ}$ corresponded to reflections from the (101), (004), (200), (105), (204), (220) and (215) crystal planes, respectively. All these diffraction peaks were assigned to anatase $\mathrm{TiO}_{2}$ (JCPDS card no. 211272). No peaks related to other phases such as rutile and brookite were observed. The broadening of the diffraction peaks indicated that the $\mathrm{TiO}_{2}$ mesoporous spheres were composed of smaller particles. Fig. 6(b) shows the Raman spectrum of the mesoporous $\mathrm{TiO}_{2}$ spheres. According to factor group theory, anatase $\mathrm{TiO}_{2}$ has six Raman active modes $\left(\mathrm{A}_{1 \mathrm{~g}}+2 \mathrm{~B}_{1 \mathrm{~g}}+3 \mathrm{E}_{\mathrm{g}}\right)$. Oshaka et al. reported that these six allowed bands were consistent with the first-order Raman spectrum. ${ }^{34}$ These bands were observed at $144\left(\mathrm{E}_{\mathrm{g}}\right), 197(\mathrm{Eg}), 399\left(\mathrm{~B}_{1 \mathrm{~g}}\right), 513$ $\left(\mathrm{A}_{1 \mathrm{~g}}\right), 519\left(\mathrm{~B}_{1 \mathrm{~g}}\right)$ and $639\left(\mathrm{E}_{\mathrm{g}}\right) \mathrm{cm}^{-1} \cdot{ }^{\mathbf{3 5 , 3 6}}$ In the current study, Raman bands of the $\mathrm{TiO}_{2}$ mesospheres at 148, 400, 518, and $640 \mathrm{~cm}^{-1}$ corresponded to the anatase phase. The observed bands were in agreement with the bands of anatase $\mathrm{TiO}_{2}$. The $\mathrm{E}_{\mathrm{g}}$ and $\mathrm{B}_{1 \mathrm{~g}}$ bands were shifted to a slightly higher wavenumber. Choi et al. attributed this shift to two main factors. The first was a contraction of nanoparticle volume caused by
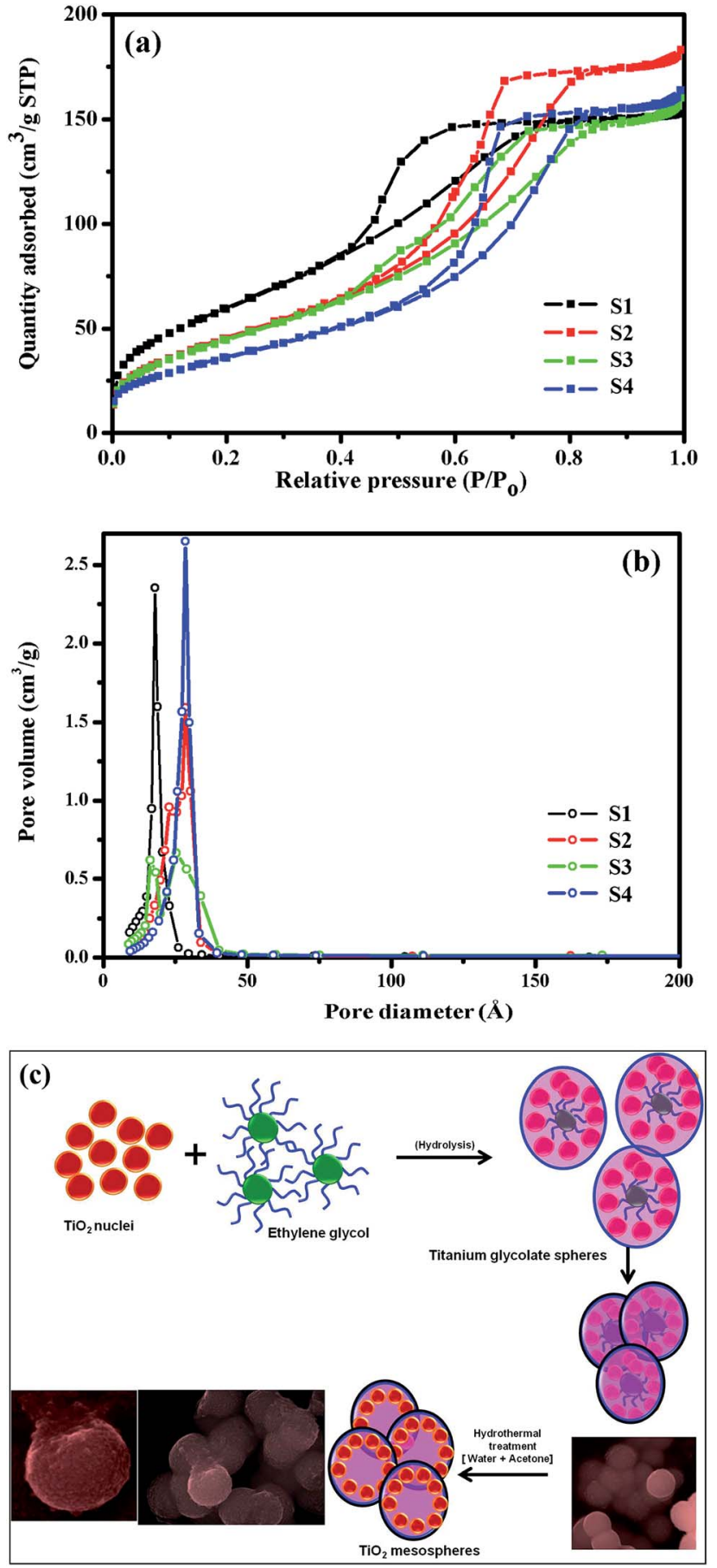

Fig. 5 (a) $\mathrm{N}_{2}$ sorption isotherms and (b) BJH pore size distribution of the mesoporous $\mathrm{TiO}_{2}$ spheres and (c) schematic formation mechanism of the mesoporous $\mathrm{TiO}_{2}$ spheres.

the radial pressure, which tends to increase the force constant $(k)$. The second was the effect of contraction, which decreases the vibrational amplitude of associating neighbor bonds, because of increased static disorder. ${ }^{37}$ The shift in Raman peaks occurred because of the decrease in particle size, because the $\mathrm{TiO}_{2}$ sample consisted of small particles as shown by HRTEM. 
Fig. 6(c) shows UV-vis absorption spectra of the samples. All samples exhibited a significant absorption onset at wavelength less than $400 \mathrm{~nm}$. This is attributed to the intrinsic band gap absorption of $\mathrm{TiO}_{2}$. An optical absorption onset in the visible region was expected, because the mesospheres possess significant light scattering capability. The $\mathrm{TiO}_{2}$ mesospheres facilitated visible photon absorption by the dye, and enhanced light
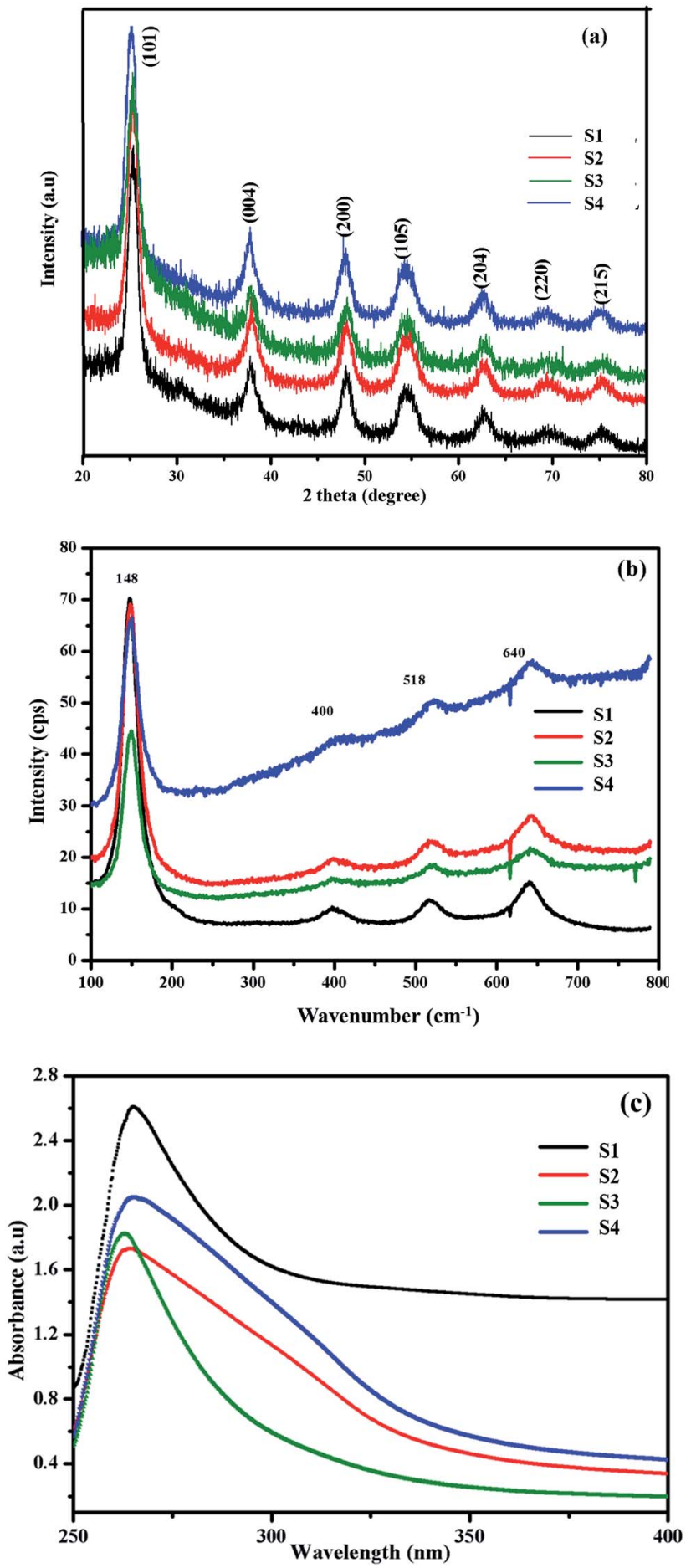

Fig. 6 (a) XRD patterns, (b) Raman spectra and (c) optical absorption spectra of the mesoporous $\mathrm{TiO}_{2}$ spheres. harvesting during DSSC performance. $\mathrm{TiO}_{2}$ mesospheres $(0.5$ $\mathrm{mL}$ of TTIP) exhibited higher absorbance compared to other samples which indicated that it possessed excellent optical properties.

The obtained $\mathrm{TiO}_{2}$ mesospheres coated photoanode $(0.5 \mathrm{~mL}$ TTIP) was cleaved to identify the nature of the deposition, interface of FTO: $\mathrm{TiO}_{2}$ mesospheres and morphology of $\mathrm{TiO}_{2}$ mesospheres. Fig. 7(a) and (b) shows the FESEM images of cross-section and top views of photoanode, respectively. The $\mathrm{TiO}_{2}$ mesospheres were well-deposited on the FTO layers and possessed the mesoporous sphere morphology as shown in the inset of the figure. Top view of the photoanode revealed that the $\mathrm{TiO}_{2}$ mesospheres were deposited uniformly without any cracks and the good interconnectivity of the mesospheres which enhances the dye adsorption and electron transport.

Fig. 7(c) shows $I-V$ curves of N719 sensitized DSSCs. Their photovoltaic parameters are summarized in Table 1 . The DSSC containing the electrode fabricated with $\mathrm{TiO}_{2}$ mesospheres $(0.5$ $\mathrm{mL}$ of TTIP) exhibited a high energy conversion efficiency of $8.96 \%$, because of its higher $J_{\mathrm{sc}}$ value of $19.09 \mathrm{~mA} \mathrm{~cm} \mathrm{~cm}^{-2}$. The DSSCs containing electrodes prepared with $1.0,1.5$ and $2.0 \mathrm{~mL}$ of TTIP exhibited gradually decreasing $J_{\mathrm{sc}}$ values of $17.72,14.77$ and $12.32 \mathrm{~mA} \mathrm{~cm}^{-2}$, yielding efficiencies of $8.43,7.22$ and $6.05 \%$, respectively. Moreover, amount of the dye adsorptions on the photoanodes were obtained using the UV visible absorption
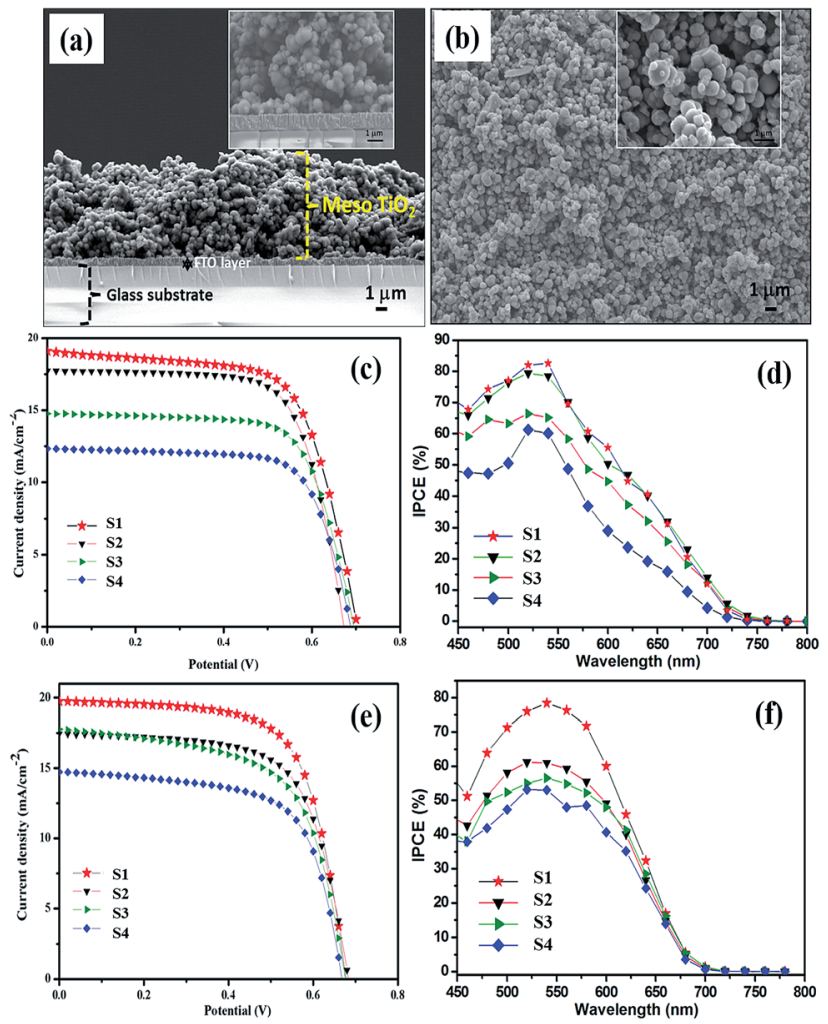

Fig. 7 FESEM images of (a) cross-section, (b) top views of mesoporous $\mathrm{TiO}_{2}$ spheres $(0.5 \mathrm{~mL}$ TTIP) coated photoanode (inset: magnified regions), (c) J-V (N719 dye), (d) IPCE characteristic curves of DSSCs (N719 dye), (e) J-V (D205 dye) and (f) IPCE characteristics of DSSCs (D205 dye). 
Table 1 Photovoltaic performance of DSSCs prepared using mesoporous $\mathrm{TiO}_{2}$ spheres sensitized by N719 dye at AM $1.5\left(100 \mathrm{~mW} \mathrm{~cm}{ }^{-2}\right)$

\begin{tabular}{lllll}
\hline Device & S1 & S2 & S3 & S4 \\
\hline Thickness $(\mu \mathrm{m})$ & $16 \pm 0.5$ & $16 \pm 0.5$ & $16 \pm 0.5$ & $16 \pm 0.5$ \\
FF & 0.66 & 0.70 & 0.70 & 0.71 \\
$V_{\text {oc }}(\mathrm{V})$ & 0.70 & 0.67 & 0.69 & 0.68 \\
$J_{\text {sc }}\left(\mathrm{mA} \mathrm{cm}{ }^{-2}\right)$ & 19.09 & 17.72 & 14.77 & 12.32 \\
EFF $(\%)$ & 8.96 & 8.43 & 7.22 & 6.05 \\
Amount of adsorbed dye & 1.95 & 1.68 & 1.33 & 1.07 \\
$\left(10^{-7}\right.$ mol cm $\left.^{-2}\right)$ & & & & \\
BET surface area $\left(\mathrm{m}^{2} \mathrm{~g}^{-1}\right)$ & 221.52 & 169.60 & 166.52 & 133.68 \\
IPCE $(\%)$ & 83.13 & 79.68 & 66.87 & 61.68 \\
$R_{\mathrm{p}}(\Omega)$ & 3.2 & 9.2 & 64.4 & 148.8 \\
\hline
\end{tabular}

spectrometer by soaking dye-sensitized photoanodes in $1 \mathrm{M}$ $\mathrm{NaOH}$ solution. The obtained results are tabulated in Table 1. The $\mathrm{TiO}_{2}$ mesospheres ( $0.5 \mathrm{~mL}$ of TTIP) coated dye-sensitized photoanodes exhibited a value of $1.95 \times 10^{-7} \mathrm{~mol} \mathrm{~cm} \mathrm{~cm}^{-2}$ and this is higher than that of other photoanodes. From the above results, it is evident that the $\mathrm{TiO}_{2}$ mesospheres (0.5 mL of TTIP) has high surface area, well-defined interconnected mesoporous network and high dye-adsorption and thus facilitated the high efficiency compared to other samples such as 1.0, 1.5 and $2 \mathrm{~mL}$ concentration of TTIP.

The incident photon to current conversion efficiency (IPCE) provide further evidence for the excellent electron transport property of mesoporous $\mathrm{TiO}_{2}$. Fig. 7(d) shows the IPCE spectra of N719 dye sensitized device prepared using 0.5, 1.0, 1.5 and $2.0 \mathrm{~mL}$ of TTIP as photoanode material. The wavelength of N719 sensitized devices is usually observed at a wavelength of 530$550 \mathrm{~nm}$, the IPCE values is observed as $83.13 \%$ for $0.5 \mathrm{~mL}$. The increase in the concentration of TTIP to $1.0,1.5$ and $2.0 \mathrm{~mL}$ led to the decrease in IPCE value to $79.68,66.87$ and $61.68 \%$. The steady decrease in IPCE value is attributed to the decrease in $I_{\mathrm{sc}}$ by increased concentration of TTIP. ${ }^{38,39}$ The improved in IPCE performance was due to enhanced charge generation efficiency, inhibition of electron recombination and high dye loading. ${ }^{\mathbf{4 0 , 4 1}}$

Metal-free D205 was also used as a sensitizer, in place of the Ru-containing N719 dye, and the performances of the resulting devices were studied. Fig. $7(\mathrm{e})$ shows the $I-V$ curves of the D205-sensitized devices and the parameters are tabulated in Table 2. Similarly to the results for the N719-sensitized DSSCs, a higher energy conversion efficiency was obtained for the $\mathrm{TiO}_{2}$ mesospheres $(0.5 \mathrm{~mL}$ of TTIP) coated DSSC. The conversion and

Table 2 Photovoltaic performance of DSSCs prepared using mesoporous $\mathrm{TiO}_{2}$ spheres sensitized by D205 dye at AM $1.5\left(100 \mathrm{~mW} \mathrm{~cm}{ }^{-2}\right)$

\begin{tabular}{lllll}
\hline Device & S1 & S2 & S3 & S4 \\
\hline Thickness $(\mu \mathrm{m})$ & $16 \pm 0.5$ & $16 \pm 0.5$ & $16 \pm 0.5$ & $16 \pm 0.5$ \\
FF & 0.67 & 0.66 & 0.61 & 0.65 \\
$V_{\text {oc }}(\mathrm{V})$ & 0.67 & 0.68 & 0.67 & 0.68 \\
$J_{\text {sc }}\left(\mathrm{mA} \mathrm{cm}^{-2}\right)$ & 19.74 & 17.40 & 17.77 & 14.74 \\
EFF $(\%)$ & 9.02 & 7.92 & 7.43 & 6.44 \\
IPCE $(\%)$ & 78.70 & 61.67 & 57.26 & 53.71 \\
$R_{\mathrm{p}}(\Omega)$ & 3.0 & 6.0 & 60.5 & 120.8
\end{tabular}

$J_{\text {sc }}$ were $9.02 \%$ and $19.74 \mathrm{~mA} \mathrm{~cm}^{-2}$, respectively. The $J_{\text {sc }}$ values were $17.77,17.40$ and $14.74 \mathrm{~mA} \mathrm{~cm}^{-2}$, and the efficiencies were 7.92, 7.43 and $6.44 \%$ for the DSSCs prepared from 1.0, 1.5 and $2.0 \mathrm{~mL}$ of TTIP, respectively. The highest efficiencies of $8.96 \%$ for N719 and $9.02 \%$ for D205 were obtained when $0.5 \mathrm{~mL}$ of TTIP was used to prepare the $\mathrm{TiO}_{2}$ mesospheres. $0.5 \mathrm{~mL}$ TTIP concentration resulted in good interconnectivity and defined boundaries, which enhanced dye adsorption and facilitated electron transport, compared with the other TTIP concentrations. Fig. 7(f) shows the incident photon to current conversion efficiency (IPCE) measured was performed on the mesoporous $\mathrm{TiO}_{2}$. D205 sensitized device has a broad absorption peak covering almost the entire visible spectra from $450-600 \mathrm{~nm}$, the IPCE values is observed as $78.70 \%$ for $0.5 \mathrm{~mL}$. With further increase in the concentration of TTIP to 1.0, 1.5 and $2.0 \mathrm{~mL}$ led to the decrease in IPCE value to $61.67,57.26$ and $53.71 \%$. To understand the interfacial charge transfer and the recombination process the electrochemical impedance spectra (EIS) were taken in the range of $(0-20 \mathrm{kHz})$. Fig. 8(a) and (b) shows the EIS spectra of the device sensitized by N719 and D205 dye sensitizers, respectively. The charge transfer resistance of the semiconductor electrolyte interface $\left(R_{\mathrm{p}}\right)$ can be calculated from the
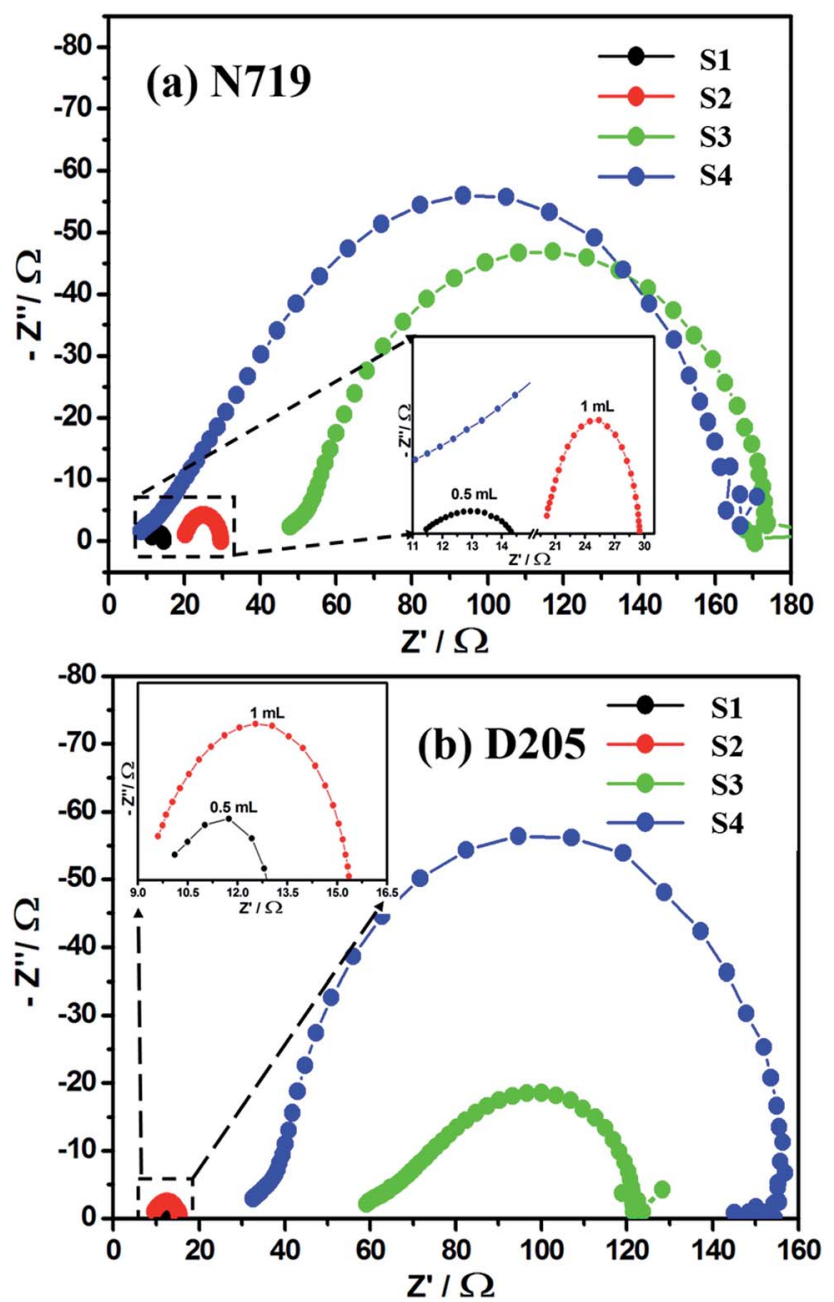

Fig. 8 EIS spectra of DSSCs prepared using the mesoporous $\mathrm{TiO}_{2}$ spheres sensitized by (a) N719 and (b) D205 dyes. 
semicircles of the spectrua. Accordingly the device using N719 as a sensitizer, the $R_{\mathrm{p}}$ value is observed as $3.2 \Omega$ for $0.5 \mathrm{~mL}$. Whereas, it increases with higher concentration as $9.2 \Omega(1.0$ $\mathrm{mL}), 64.4 \Omega(1.5 \mathrm{~mL})$ and $148.8 \Omega(2.0 \mathrm{~mL})$. Similarly, in the case of $\mathrm{D} 205$ it is noted as $3.0 \Omega$ for $0.5 \mathrm{~mL}$ and $6.0 \Omega(1.0 \mathrm{~mL}), 60.5 \Omega$ $(1.5 \mathrm{~mL})$ and $120.8 \Omega(2.0 \mathrm{~mL})$. In general, the decrease in the $R_{\mathrm{p}}$ value represents the enhancement in the dye adsorption. ${ }^{\mathbf{4 2 , 4 3}}$ Thus it is worthy to note in both the cases of N719 and D205 as sensitizers the $R_{\mathrm{p}}$ value is lower for the $0.5 \mathrm{~mL}$. It has the good agreement with the TEM and $I-V$ measurements.

\section{Conclusions}

High surface area mesoporous anatase $\mathrm{TiO}_{2}$ nanospheres were synthesized by solvothermal growth using ethylene glycol as a template. The effect of the precursor TTIP concentration on the morphology, structure, and optical properties of the mesoporous $\mathrm{TiO}_{2}$ nanospheres was investigated. $\mathrm{TiO}_{2}$ nanospheres were characterized by FESEM, TEM, $\mathrm{N}_{2}$ sorption measurements, XRD, Raman spectroscopy and UV-vis absorption spectrophotometry. A TTIP concentration of $0.5 \mathrm{~mL}$ resulted in excellent interparticle connection with well-defined boundaries, compared with higher TTIP concentrations (1.0, 1.5 and 2.0 $\mathrm{mL}$ ). The $\mathrm{TiO}_{2}$ mesospheres were used to prepare photoanodes, and the performances of the resulting DSSCs were studied. The effect of the sensitizers N719 and D205 on device performance was investigated. A maximum efficiency of $8.96 \%$ was achieved when using N719, and that of $9.02 \%$ was achieved when using D205, at a TTIP concentration of $0.5 \mathrm{~mL}$ for a thickness of $16 \mu \mathrm{m}$.

\section{Acknowledgements}

This work was financially supported by Grant-in-Aid for Scientific Research (B) (25289087), Grant-in-Aid for JSPS Fellows (2412363, 25-13360) from the Ministry of Education, Culture, Sports, Science and Technology of Japan, and the cooperative research projects of the Research Institute of Electronics, Shizuoka University. The authors would like to thank Center for Instrumental Analysis, Shizuoka University, Hamamatsu, Japan for the characterization techniques. We thank Prof. K. Murakami, Prof. Masayuki Okuya for $I-V$ and IPCE measurements. J. Archana would like to thank JSPS, Japan, for their award of JSPS research fellowship.

\section{References}

1 B. O'Regan and M. Gratzel, Nature, 1991, 353, 737-740.

2 J. Lin, L. Zhao, Y.-U. Heo, L. Wang, F. H. Bijarbooneh, A. J. Mozer, A. Nattestad, Y. Yamauchi, S. X. Dou and J. H. Kim, Nano Energy, 2015, 11, 557-567.

3 J. Lin, Y.-U. Heo, A. Nattestad, Y. Yamauchi, S. X. Dou and J. H. Kim, Electrochim. Acta, 2015, 153, 393-398.

4 H. J. Snaith, Adv. Funct. Mater., 2010, 20, 13-19.

5 G. J. Meyer, ACS Nano, 2010, 4, 4337-4343.

6 M. Gratzel, Inorg. Chem., 2005, 44, 6841-6851.
7 T. Yamaguchi, N. Tobe, D. Matsumoto, T. Nagai and H. Arakawa, Sol. Energy Mater. Sol. Cells, 2010, 94, 812-816.

8 J. Kim, J. K. Koh, B. Kim, J. H. Kim and E. Kim, Angew. Chem., Int. Ed., 2012, 51, 6864-6869.

9 I. Robel, V. Subramanian, M. Kuno and P. V. Kamat, J. Am. Chem. Soc., 2006, 128, 2385-2393.

10 J. K. Koh, J. Kim, B. Kim, J. H. Kim and E. Kim, Adv. Mater., 2011, 23, 1641-1646.

11 Y. Saito, S. Kambe, T. Kitamura, Y. Wada and S. Yanagida, Sol. Energy Mater. Sol. Cells, 2004, 83, 1-13.

12 M. Y. Song, D. K. Kim, K. J. Ihn, S. M. Jo and D. Y. Kim, Nanotechnology, 2004, 15, 1861-1865.

13 H. G. Jung, C. S. Yoon, J. Prakash and Y. K. Sun, J. Phys. Chem. C, 2009, 113, 21258-21263.

14 C. Yasuo, I. Ashraful, W. Yuki, K. Ryoichi, K. Naoki and H. Liyuan, Jpn. J. Appl. Phys., 2006, 45, 638-640.

15 Y. Wang, X. Tang, L. Yin, W. Huang, Y. R. Hacohen and A. Gedanken, Adv. Mater., 2000, 12, 1183-1186.

16 P. Kluson, P. Kacer, T. Cajthaml and M. Kalaji, J. Mater. Chem., 2001, 11, 644-651.

17 M. Gratzel, Curr. Opin. Colloid Interface Sci., 1999, 4, 314-321. 18 X. Lu, G. Li and J. C. Yu, Langmuir, 2010, 26, 3031-3039.

19 S. Liu, J. Yu and C. Jaronie, J. Am. Chem. Soc., 2010, 132, 11914-11916.

20 A. Sung Hoon, K. Joo Hwan, S. Jin Ah and K. Jong Hak, Chem. Commun., 2010, 46, 1935-1937.

21 G. Satyanarayana Reddy, A. Krishnamoorthy, Y. Chrisotpher, M. Gratzel and B. Palani, Energy Environ. Sci., 2010, 3, 838-845.

22 J. Hun Gi, K. Yong Soo and S. Yang kook, Electrochim. Acta, 2010, 55, 4637-4641.

23 M. Xiaohuan, P. Kai, P. L. Yong, Z. Wei, P. Qingjiang, T. Guohui and W. GuoFeng, J. Mater. Chem. A, 2013, 1, 9853-9861.

24 Y. Xiong, D. He, Y. Jin, P. J. Cameron and K. J. Edler, J. Phys. Chem. C, 2015, 119, 22552-22559.

25 J. D. Peng, C. P. Lee, D. Velayutham, V. Suryanarayanan and K. C. Ho, J. Mater. Chem. A, 2015, 3, 6383-6391.

26 J. R. Deka and H. W. Wang, J. Chin. Chem. Soc., 2014, 61, 1049-1055.

27 P. Chen, J. D. Peng, C. H. Liao, P. S. Shen and P. L. Kuo, J. Nanopart. Res., 2013, 15, 1465-1476.

28 S. L. Chang, Y. L. Jung, S. C. Won and H. K. Jong, Electrochim. Acta, 2015, 173, 139-147.

29 T. Luo, P. Hao, X. Haixian, Y. Ang, X. Meigui, C. Qingli, C. Yuming and Z. Xingfu, Solid State Sci., 2012, 14, 616-621.

30 H. Tong, N. Enomoto, M. Inada, Y. Tanaka and J. Hojo, Mater. Lett., 2015, 141, 259-262.

31 J. Archana, M. Navaneethan and Y. Hayakawa, J. Power Sources, 2013, 242, 803-810.

32 E. A. Barringer and H. K. Bowen, Langmuir, 1985, 1, 414-420. 33 S. H. Kang, S. H. Choi, M. S. Kang, J. Y. Kim, H. S. Kim, T. Hyeon and Y. E. Sung, Adv. Mater., 2008, 20, 54-58.

34 T. Ohsaka, J. Phys. Soc. Jpn., 1980, 48, 1661-1668.

35 B. Karunagaran, K. Kim, D. Mangalraj, J. Yi and S. Velumani, Sol. Energy Mater. Sol. Cells, 2005, 88, 199-208.

36 Y. Li, Y. Duan and W. Li, Spectrosc. Spectral Anal., 2000, 20, 699-701. 
37 C. Hyun Chul, J. Young Mee and K. Seung Bin, Vib. Spectrosc., 2005, 37, 33-38.

38 P. Cheng, P. Sun, S. Du, Y. Cai, X. Li, Z. Wang, F. Liu, J. Zheng and G. Lu, RSC Adv., 2014, 4, 23396-23404.

39 R. G. Satyanarayanan, Y. Chrisopher and B. Palani, J. Mater. Chem., 2012, 22, 10873-10882.
40 Z. Yan-Zhen, D. Haiyang, L. Yu, T. Xia, C. Guozhong and C. Jian-Feng, J. Power Sources, 2014, 254, 153-160.

41 Z. Yang, C. Y. Chen, C. W. Liu and H. T. Chang, Adv. Energy Mater., 2011, 1, 259-264.

42 S. F. Shaikh, R. S. Mane and O. S. Joo, RSC Adv., 2014, 4, 35919-35927.

43 H. J. Snaith and C. Ducati, Nano Lett., 2010, 10, 1259-1265. 